\title{
Optimizing Peach Tree Canopy Architecture for Efficient Light Use, Increased Productivity and Improved Fruit Quality
}

\author{
Brendon M. Anthony and Ioannis S. Minas *
}

check for updates

Citation: Anthony, B.M.; Minas, I.S. Optimizing Peach Tree Canopy Architecture for Efficient Light Use, Increased Productivity and Improved Fruit Quality. Agronomy 2021, 11, 1961. https://doi.org/10.3390/ agronomy11101961

Academic Editors:

José Casanova-Gascón, Ignasi Iglesias, Stefano Musacchi and

Salvatore Camposeo

Received: 1 August 2021

Accepted: 23 September 2021

Published: 29 September 2021

Publisher's Note: MDPI stays neutral with regard to jurisdictional claims in published maps and institutional affiliations.

Copyright: (c) 2021 by the authors. Licensee MDPI, Basel, Switzerland. This article is an open access article distributed under the terms and conditions of the Creative Commons Attribution (CC BY) license (https:/ / creativecommons.org/licenses/by/ $4.0 /)$.
Department of Horticulture and Landscape Architecture, Colorado State University, Fort Collins, CO 80523, USA; brendon.anthony@colostate.edu

* Correspondence: ioannis.minas@colostate.edu

\begin{abstract}
Peach production in the USA has been in decline in recent decades due to poor fruit quality, reduced consumption and increased cost of production. Productivity and fruit quality can only be enhanced in the orchard through optimizing preharvest factors such as orchard design and training systems. Transition from low-density plantings (LDP) to high-density plantings (HDP) in peach is associated with the availability of reliable size controlling rootstocks. Increased densities must be combined with modern training systems to diffuse vigor and further increase light interception and yields, while optimizing light distribution, fruit quality and cost of production. Several training systems have been tested in peach with various objectives and goals, such as increasing light, water use and labor efficiencies, along with designing canopy architectures to facilitate mechanization and robotics. In general, increased planting densities increase yields, but excessive densities can promote shade, while excessive crop load can deteriorate quality. An ideal peach cropping system should optimize light interception and light distribution to balance maximum yield potential with maximum fruit quality potential. Successful management of high-density peach fruiting wall systems can lead to enhanced and uniform fruit quality, and ensure a sustainable industry.
\end{abstract}

Keywords: training systems; orchard design; high-density planting; HDP; preharvest factors; land use efficiency; pomology

\section{Introduction}

Peach (Prunus persica (L.) Batsch.) is ranked as the 6th most important tree fruit crop in the world. China is the number one producer of peaches worldwide at nearly 15 million metric tons (MMt) per year, with Spain (1.8 MMt), Italy (1.3 MMt), Greece (0.9 MMt) and the United States (US) (0.8 MMt) ranked as the 2nd-5th producers, respectively [1]. Within the United States, the top seven producing states (in order) include: California, South Carolina, Georgia, New Jersey, Pennsylvania, Washington and Colorado [2]. California produces over 500,000 tons per year for a total value of USD 350 million, while in Colorado, production is far less, at nearly 15,000 tons per year for a total value of USD 35 million.

Global peach consumption per capita has experienced significant decreases over the past few decades. In the US alone, peach consumption per capita has been constantly decreasing to $1.3 \mathrm{~kg} /$ person, at present day [3] (Figure 1). Consumer surveys have revealed that the reason peach consumption has declined is due to poor quality fruit that are tasteless, not at optimum maturity (e.g., overripe, too green) or have abnormal texture due to postharvest disorders [4]. The decreased demand for peaches in US is driving peach production down, as peach prices in the major producing state (CA) are low in a steady increasing cost of production (Figure 1).

Interestingly, there is still demand for high-quality peaches and consumers are still willing to pay additional money for them. For example, in CA, the top peach producer in US, the farmgate price for peaches is nearly USD $0.6 \mathrm{~kg}^{-1}$ [2], while in CO, where the highest farmgate price per $\mathrm{kg}$ in the country is recorded, the price is at USD $2.2 \mathrm{~kg}^{-1}$ [2]. This increased farmgate price is attributed as a "quality premium", due to the exceptional 
quality of Colorado peaches. Colorado's increased quality is a result of the climate (warm days/cool nights), frequent spring frosts leading to low crop loads and access to local markets, which enables harvesting at the "tree ripe" stage (fruit firmness between 30 and $36 \mathrm{~N}$ ) [3]. This example demonstrates the strong relationship between peach fruit quality and the profitability/sustainability of the peach industry.
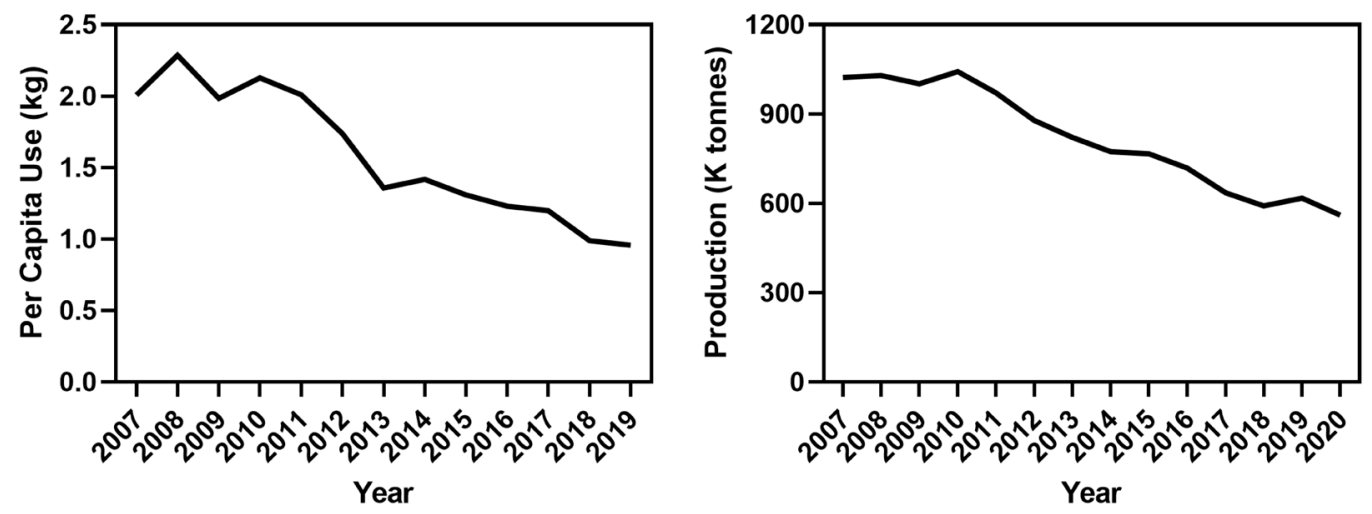

Figure 1. Peach production is declining in the United States, along with fresh peach/nectarine consumption per capita (USDA-NASS, 2021).

To ensure a sustainable peach industry worldwide, reducing the cost of production, increasing yields and improving fruit quality must be the main focus for producers, researchers and breeders alike [3]. Peach fruit quality can only be developed and enhanced in the orchard through the optimization of preharvest factors, while quality can only be maintained postharvest [4]. Influential preharvest factors that impact fruit quality include: cultivar and rootstock selection, crop load management, fruit position in the canopy, irrigation, fertilization, pruning and training systems [3] (Figure 2).

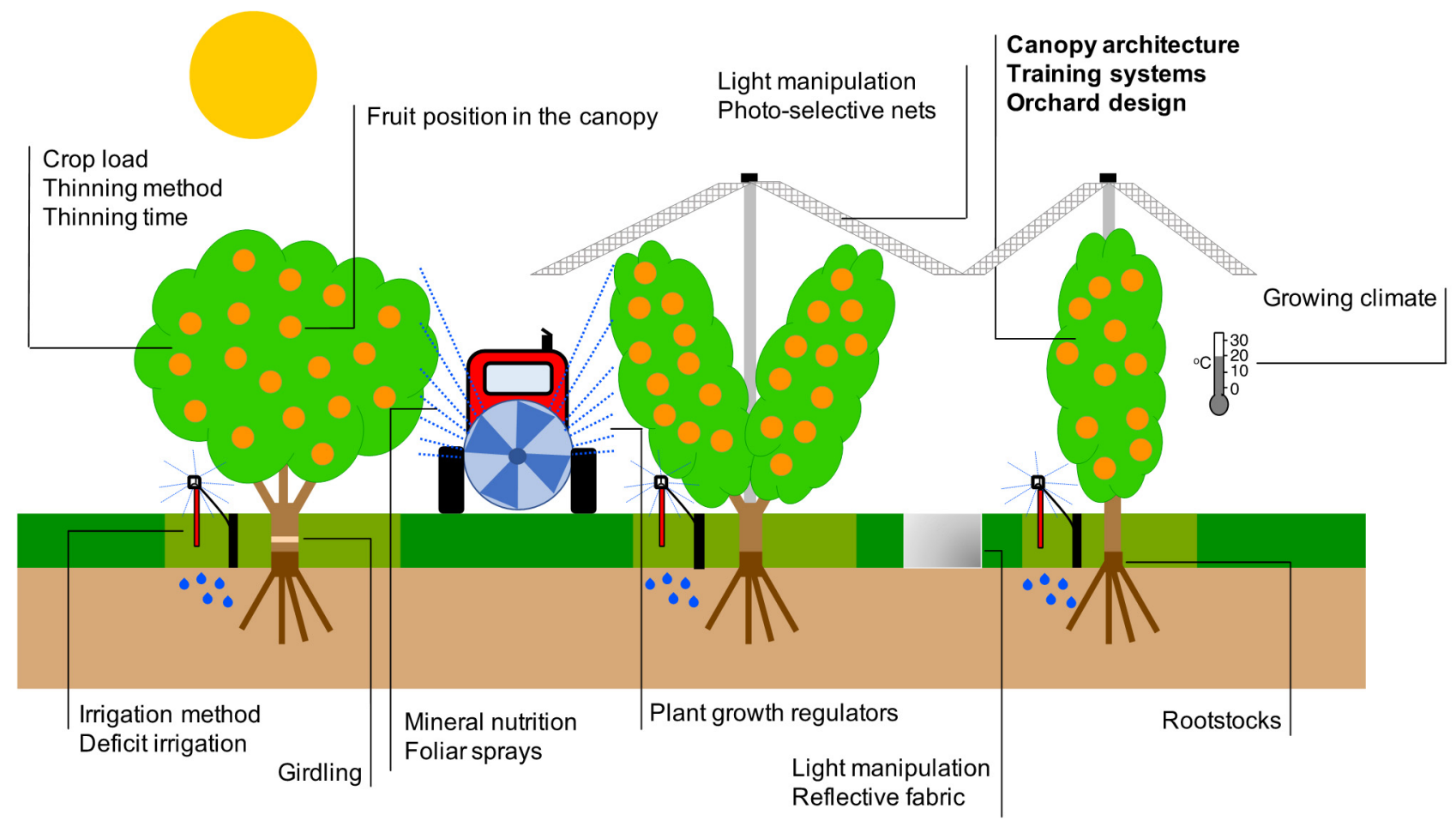

Figure 2. Overview of key orchard factors that influence preharvest peach tree and fruit physiology and affect harvest quality (Adapted from Minas et al. [3]). 
Training systems manipulate the canopy architecture to achieve various goals of producers. In short, an ideal training system maintains optimal levels of light interception, uniform light distribution and facilitates high yields of high-quality fruit. This article provides a focus on the development and modernization of training systems in peach production, and how they are being optimized.

\section{Fruit Quality}

Fruit quality is defined by various properties, such as sensorial (e.g., appearance, texture, taste, aroma), mechanical (e.g., mass, volume, density, firmness) and nutritional value properties (e.g., vitamins, antioxidants, polyphenols) [5]. A producer may define quality by the characteristics that improve pack-out and profitability (e.g., fruit weight, size, free of defects, etc.), while a consumer may prioritize sensory, nutritional and safety aspects. Overall, to increase peach consumption, growers and researchers alike must be focused on improving the characteristics customers desire, such as taste, sweetness, color and aroma to encourage repeat sales [4].

Generally, peach quality is linked to the sugar content and sugar/acid ratio in the fruit, which is perceived as sweetness [6]. Industry standards for optimal peach quality currently range between $\sim 10$ and $12 \%$ soluble solids concentration (SSC) (or Brix ${ }^{\circ}$ ), depending on the cultivar, along with titratable acidity (TA) levels below 0.7\% [3,6-8]. Another critical parameter in respect to fruit quality is dry matter content (DMC, \%) and is highly correlated with SSC [9]. Previous studies in other tree fruit crops have demonstrated significant relationships between elevated DMC levels and increased consumer acceptance [3]. Another critical component of postharvest and consumer performance is flesh firmness (FF) at harvest, which has historically characterized maturity status, along with ground color observations. In general, fruits exhibiting FF values between 45-54 N are classified as "well-mature" or noted as the "commercial harvest" stage, as they are less susceptible to bruising and can be stored/shipped longer. Fruits that are less firm (30-36 N) at harvest are known as "tree ripe", cannot be stored/shipped long and must be sold locally. However, FF values and their corresponding physiological maturity stage are influenced by the flesh texture typology, as some types such as "non-melting" or "stony hard", may delay softening or never become soft [10]. However, one critical consideration in respect to quality and maturity, is that fruit that are more mature will have improved quality.

As a climacteric fruit, peach undergoes a spike of ethylene during ripening, accompanied by a peak in respiration, which translates into a cascade of highly regulated physicochemical changes [11]. Throughout maturation and ripening "on-tree", DMC and SSC increase, FF and TA decrease, pigments are accumulated, and aromatics are volatilized, all of which contribute to organoleptic attributes that consumers perceive and prefer [5]. Several preharvest factors influence both maturity and quality at harvest [3] (Figure 2). Therefore, when conducting pomological experiments, it is critical to control for maturity in order to understand the true impact of pre- and postharvest treatments on fruit quality [12]. However, until recently, controlling for maturity was extremely difficult to do, as destructive methods (e.g., FF assessment) are labor intensive, sample size limiting and not always indicative of the true physiological maturity status of the fruit [9]. Further, ground color measurements to assess physiological maturity are subjective and cannot apply to cultivars that demonstrate a fully red overcolor early in the season, which has led to premature picks of immature/poor quality fruit in the past [9]. With recent advancements in technology and the development of an index for maturity known as the index of absorbance difference $\left(\mathrm{I}_{\mathrm{AD}}\right)[13,14]$, physiological maturity assessments and subsequent confounding variable control can be carried out rapidly, non-destructively and over a large sample size of fruit [9]. This index can be integrated into open-source handled near-infrared spectroscopy (NIRS) instruments, along with additional parameters such as SSC and DMC, to evaluate both peach fruit maturity and quality rapidly and accurately in a single-scan [9].

Several experiments have been conducted to evaluate the role of preharvest factors such as rootstocks and training systems on peach fruit quality, but have failed to control 
for maturity. In fact, these results are limited in application with a confounding variable present. Therefore, future studies should aim to control for maturity in their experimental design to better understand the true impact these preharvest factors have on fruit quality development [12].

\section{Rootstocks}

Before training systems can be discussed, an investigation into the pre-existing and new rootstock cultivars is imperative as tree size and vigor dictates the feasibility and optimization of any training system, canopy architecture and orchard design. Rootstocks provide a horticultural tool to control scion vigor, increase yields and yield efficiency and facilitate canopy architecture arrangements that can improve fruit quality [15]. Typical challenges peach producers face in respect to soils, include high bulk density, high $\mathrm{pH}$, nematodes, fungal pathogens, orchard replant disease syndrome, and texture issues (e.g., too clayey/too sandy) [15]. These challenges promote objectives for rootstock breeding programs worldwide, so producers can ameliorate these difficulties through optimal selection of a particular rootstock genotype for specific pedoclimatic conditions.

Historically, peach has been planted into low-density plantings (LDPs), which are characterized by wide inter- and intra-row (i.e., between trees) spacings with vigorous peach seedling (P. persica) rootstocks. Although these peach seedling rootstocks have long been the mainstay of peach production globally, they are increasingly being criticized for their: inability to control tree vigor, withstand high soil $\mathrm{pH}$ and tolerate drought/waterlogging, nematodes, crown gall, fungal pathogens and replant disease $[15,16]$. However, due to increased production costs, lack of pest control efficacy or resistances, and diminishing land available for fruit production, the development of interspecific Prunus rootstocks to overcome these abiotic, biotic and resource challenges has begun.

Several new genotypes are being bred all over the world in countries such as the US, Spain, Italy, Russia and France (Table 1, Figure 3). In particular, several interspecific Prunus hybrids, almond species and plum species are replacing the traditional peach seedling rootstocks in Europe and North America and are characterized by different vigor classifications $[17,18]$. (Table 1, Figure 3). In particular, 'GF 667', a peach $x$ almond hybrid, has found tremendous success in European peach production due to its ability to resist nematode infestation, replant disease, thrive in calcerous, poor and/or arid soils and be propagated easily in the nursery [19]. However, it maintains a vigorous classification and inhibits the potential of exploiting the advantages of higher-density plantings [19]. Characteristics now being considered in the breeding process for these new stocks include: propagation behavior, graft compatibility, vigor control, production efficiency and fruit quality $[17,18,20]$.

Table 1. Peach rootstock genotypes and breeding programs around the world.

\begin{tabular}{|c|c|c|}
\hline Rootstock & Country Origin & Genetic Origin \\
\hline Controller $\mathrm{TM}_{5}$ (K146-43) & UC-Davis *, CA, USA & P. salicina $\times P$. persica \\
\hline Controller ${ }^{\mathrm{TM}_{6}}$ (HBOK 27) & UC-Davis, CA, USA & P. persica $\times$ P. persica \\
\hline Controller $\mathrm{TM}_{7}$ (HBOK 32) & UC-Davis, CA, USA & P. persica $\times P$. persica \\
\hline Controller ${ }^{\mathrm{TM}_{8}}$ (HBOK 10) & UC-Davis, CA, USA & $P$. persica $\times P$. persica \\
\hline MP-29 & University of Florida, FL, USA & P. umbellata $\times$ P. persica \\
\hline P. americana & USA & P. americana \\
\hline Lovell & G.W. Thissell, Winters, CA, USA & P. persica \\
\hline Hansen 536 & UC-Davis, CA, USA & P. amygdalus $\times$ P. persica \\
\hline KV 10123 & USDA Kearneysville, WV, USA & P. persica \\
\hline KV 10127 & USDA Kearneysville, WV, USA & P. persica \\
\hline Nemaguard & USDA, USA & P. persica $\times P$. davidiana \\
\hline Guardian $^{\circledR}$ & USDA/Clemson, SC, USA & P. persica \\
\hline Bright's Hybrid \#5 & Brights Nursery, CA, USA & P. dulcis $\times$ P. persica \\
\hline Viking & Zaiger Genetics, inc., CA, USA & unknown interspecific cross \\
\hline Atlas & Zaiger Genetics, inc., CA, USA & unknown interspecific cross \\
\hline Rootpac ${ }^{\circledR} \mathrm{R}$ & Agromillora, Spain & P. cerasifera $\times$ P. amygdalus \\
\hline
\end{tabular}


Table 1. Cont.

\begin{tabular}{|c|c|c|}
\hline Rootstock & Country Origin & Genetic Origin \\
\hline Rootpac ${ }^{\circledR} 70$ & Agromillora, Spain & P. persica $\times($ P. amygdalus $\times$ P. persica $)$ \\
\hline Rootpac ${ }^{\circledR} 40$ & Agromillora, Spain & $\begin{array}{c}(P . \text { dulcis } \times \\
\text { persica })\end{array}$ \\
\hline Rootpac ${ }^{\circledR} 20$ & Agromillora, Spain & P. besseyi $\times P$. persica \\
\hline Microbac (Replantpac) & Agromillora, Spain & P. domestica \\
\hline Fortuna & Russia & P. cerasifera $\times P$. persica \\
\hline Krymsk $^{\circledR} 1$ & Krymsk Exp. Breeding Station, Russia & P. tomentosa $\times P$. cerasifera \\
\hline Krymsk $^{\circledR} 86$ & Krymsk Exp. Breeding Station, Russia & $P$. cerasifera $\times P$. persica \\
\hline Empyrean ${ }^{\circledR} 2$ (Penta) & ISF, Italy & P. domestica \\
\hline Empyrean ${ }^{\circledR} 3$ (Tetra) & ISF, Italy & P. domestica \\
\hline Imperial California & Italy & P. domestica \\
\hline GF677 & INRA, France & P. amygdalus $\times$ P. persica \\
\hline
\end{tabular}

* UC-Davis = University of California, Davis; USDA = United States Department of Agriculture; ISF = Istituto Sperimentale per la Frutticoltura; INRA = Institut National de la Recherche Agronomique.

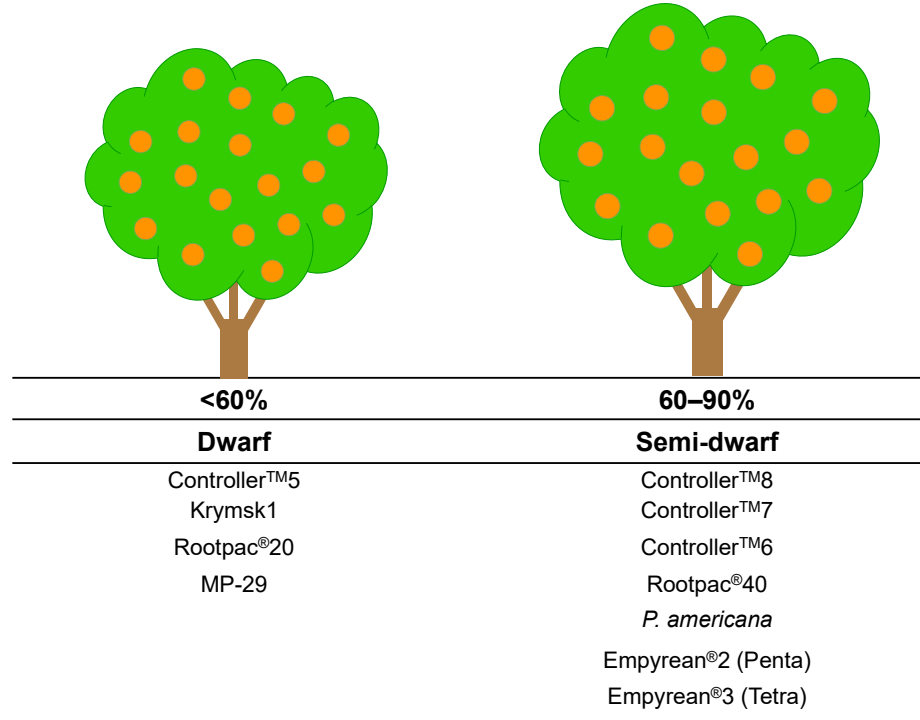

Figure 3. Peach rootstock genotypes and their vigor classification. Vigor classification is bracketed as follows: vigorous rootstocks are $>110 \%$ the size of Lovell with the size estimated by trunk cross-sectional area (TCSA); standard size rootstocks are $110-90 \%$ of Lovell size; semi-dwarfing rootstocks are $60-90 \%$ of Lovell and dwarfing rootstocks are $<60 \%$ the size of Lovell (vigor classification adopted from Reighard et al. [18]).

In the USA, the USDA, public universities, and private institutions have contributed to rootstock breeding. In the early 20th century, the various breeding programs goals were originally focused on identifying seedling genotypes with resistances to abiotic and biotic factors. In particular, nematode resistance was a large research priority, in which popular cultivars such as Nemaguard and Guardian ${ }^{\circledR}$ were developed and released. More recently, the University of California at Davis (UC-Davis) in the USA, was focused on developing peach-almond hybrids that can withstand calcareous soils with high $\mathrm{pH}$, in which 'Hansen 536' was developed [15]. Similarly, private entities such as Bright's Nursery, inc. released their Bright's Hybrid ${ }^{\circledR}$ series and Zaiger Genetics, inc. released other interspecific rootstocks such as 'Viking', 'Citation' and 'Atlas' [15]. In general, these rootstocks were developed to withstand issues with soil characteristics and pests, and not necessarily bred to control for vigor. 
In the USA, a working group known as the North Central (NC) Regional Research Project 140 (NC-140) evaluates several new and existing rootstocks across the country through multi-state collaborative experimental trials [17,18,21]. Among other important temperate tree fruit species NC-140 seeks to evaluate the compatibility and performance of Prunus rootstocks with peach cultivars across several states and years $[17,18]$.

A primary focus of recent rootstock selection efforts is vigor control, as to facilitate higher density plantings, similar to the transition in apple and cherry [22-26]. Although dwarfing rootstocks have been bred, some genotypes negatively impact fruit size, as the vigor control mechanism in particular genotypes restricts xylem vessel diameter. Two series of Prunus interspecific hybrid rootstocks that have demonstrated promising size controlling genotypes include: the Controller ${ }^{\mathrm{TM}}$ series from UC-Davis, USA and the Rootpac $^{\circledR}$ series from Agromillora, Spain (Table 1, Figure 3). Several of these genotypes are currently under evaluation in current NC-140 trials in the USA [27]. In sum, dwarfing hybridized Prunus rootstocks, with various abiotic/biotic resistances, are becoming more and more available, which are facilitating the advancement of training system innovation and increased planting densities for peach production worldwide.

\section{Training Systems}

Peach training systems span from traditional, complex 3D canopy architectures, with multiple leaders per tree, to more modern high-density, simple/planar designs with single or multiple leaders per tree. The shift to modern orchard design is facilitated by genetic and horticultural manipulations that control vigor (e.g., low-vigor cultivars, dwarfing rootstocks, pruning/training, etc.) in order to increase planting density, production per hectare, light interception, light distribution and fruit quality $[28,29]$. Some of the main training systems for peach include: low to medium density multi-leader systems such as open vase, delayed vasette, Quad-V and Hex-V, along with higher density systems such as palmette/hedgerow, Y-shaped (e.g., Kearney Agriculture Center-V (KAC-V), bi-axis), and central leaders (e.g., Fusetto, Tall Spindle Axe (TSA), Slender Spindle Axe (SSA)) (Table 2, Figures 4 and 5) [3,30].

Table 2. Training systems and their associated orchard design characteristics.

\begin{tabular}{|c|c|c|c|c|}
\hline System & $\begin{array}{l}\text { No. of Primary } \\
\text { Leaders }\end{array}$ & $\begin{array}{l}\text { Spacing (m) } \\
\text { (Intra- } \times \\
\text { Inter-Row) }\end{array}$ & Trees ha ${ }^{-1}$ & Tree Height (m) \\
\hline \multicolumn{5}{|c|}{ Low-Density Planting (LDP) } \\
\hline Open Vase & 3 & $3.5-5.0 \times 4.0-5.0$ & $220-550$ & $2.2-5.0$ \\
\hline \multicolumn{5}{|c|}{ Medium-Density Planting (MDP) } \\
\hline Delayed Vasette & 4 & $3.5 \times 4.5$ & $600-800$ & $3.0-4.0$ \\
\hline Palmette & 1 & $2.0-3.5 \times 4.0-4.5$ & $600-900$ & $3.5-4.5$ \\
\hline Hex-V & 6 & $3.0 \times 4.5$ & 750 & $2.0-2.5$ \\
\hline Quad-V & 4 & $2.5-3.0 \times 4.5$ & $900-1000$ & $2.5-3.0$ \\
\hline \multicolumn{5}{|c|}{ High-Density Planting (HDP) } \\
\hline Fusetto or Tall Spindle Axe (TSA) & 1 & $1.5-2.0 \times 4.0$ & $1250-2000$ & $2.8-3.5$ \\
\hline Slender Spindle Axe (SSA) & 1 & $1.2-1.5 \times 3.5-4.0$ & $1500-2445$ & $3.0-3.7$ \\
\hline Y-Shaped (Bi-Axis, KAC-V) & 2 & $1.5-2.0 \times 4.0-4.5$ & 900-2000 & $3.0-5.5$ \\
\hline Cordon Systems & $1-2$ & $2.4 \times 4.0$ & 900 & $<2.5$ \\
\hline \multicolumn{5}{|c|}{ Ultra High-Density Planting (UHDP) } \\
\hline Meadow Orchard & $1-2$ & $0.4-1.0 \times 1.3-4.8$ & $2700-19,000$ & $1.5-2.2$ \\
\hline
\end{tabular}

Traditional multi-leader 3D systems, such as the open vase and delayed vassette, can yield a higher amount of fruit per tree, given the larger canopy volume, but these systems produce less on a per land area basis given their lower densities [29]. Additionally, these 
canopies may intercept a higher amount of light at the top/exterior portions of the tree, but often the bottom/internal portions are shaded. This is especially true for peach trees, as $80 \%$ of leaves are located in the top $40 \%$ of the tree in these 3D systems [31]. Génard and Baret [32] demonstrated the variability of light distribution in open vase systems, reporting that $30 \%$ of shoots received $<30 \%$ of available light, which is below the critical threshold for floral bud induction [30]. The shade in these interior/basal portions of the canopy, especially in high vigor cultivars/rootstocks, leads to reduced tree performance, yields and fruit quality (reduced color and SSC) [33]. Subsequently, this can lead to lower crop loads in the lower/interior parts of the canopy and an excessive vegetative vigor response, which can only exacerbate the problem of poor light distribution, unless summer pruning (or other vigor control) interventions are used. Grossman and DeJong [29] reported that open vase systems intercepted less light and produced less $\left(\mathrm{Mt} \mathrm{ha}^{-1}\right)$ than higher density 2D cordon and KAC-V systems. Furthermore, these smaller tree, high-density planting (HDP) training systems facilitate better light distribution, so interior/basal portions of the canopy do not decline in yields and can maintain higher crop loads [34]. Nuzzo et al. [35] confirms this trend, reporting that when comparing a Y-system with an open vase system in peach, the Y-system resulted with higher levels of leaf area index (LAI, leaf area: ground area), light interception (LI, \%) and yields. However, it is important to note that training system selection, along with its pruning/management, must be contextualized to cultivar/rootstock selection [36].

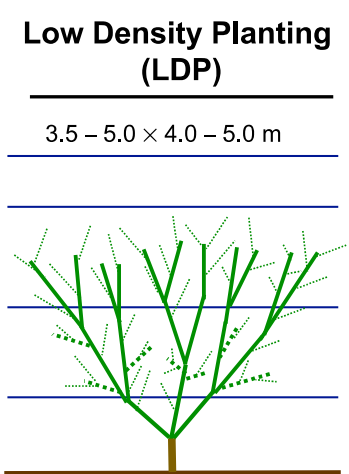

Open vase

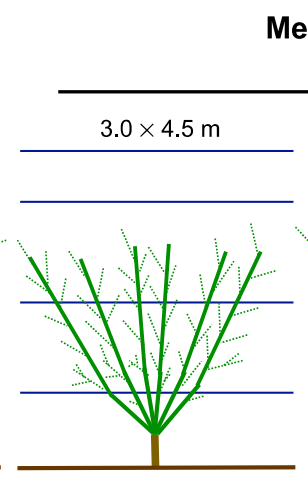

Hex-V
Medium Density Planting

(MDP)

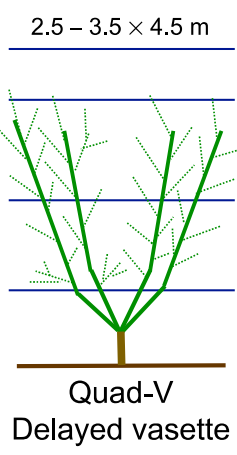



Palmette
High Density Planting (HDP)



Bi-Axis

Figure 4. Canopy architectures of the most widely used training systems in peach and their planting densities. Spacings listed as: intra-row $\times$ inter-row.

\subsection{Low-Density Planting Systems}

Low-density plantings (LDP) generally include 200-550 trees per hectare, with heights ranging from $2.2-5.0 \mathrm{~m}$, as inter-rows are typically wider $(4.0-5.0 \mathrm{~m})$ and can facilitate taller trees (Table 2). These systems are accompanied with more vigorous rootstocks and generate larger canopies, when compared to other medium-density planting (MDP) and HDP systems. The most notable peach training system, open vase, along with other free standing multi-leader systems, typically do not require trellising, as the permanent scaffolds and structure are strong enough to support the fruit load alone. This, paired with the reduced number of trees required at planting can minimize orchard establishment costs. However, their light interception remains low on a per hectare basis $(<50 \%)$, and their lack of uniform light distribution leads to yield and quality deficits [29].

Open Vase

The open vase system has been the traditional training system for peach production worldwide. In CA, it has been the dominant system for over a century and continues to be the most widely used in the state, as well as in most major peach producing countries 
around the world $[20,37]$. The open vase typically consists of three to five primary scaffolds emanating from a short trunk and will split into secondary/tertiary scaffolds deriving from each primary scaffold [37]. Open vase plantings include planting densities of 3.5-5.0 (intra-row) $\times$ 4.0-5.0 (inter-row) (Table 2, Figures 4 and 5) and can be arranged in either a square/rectangle, offset square/diamond or hexagonal/equilateral triangle design to manipulate land/light use efficiency [38].

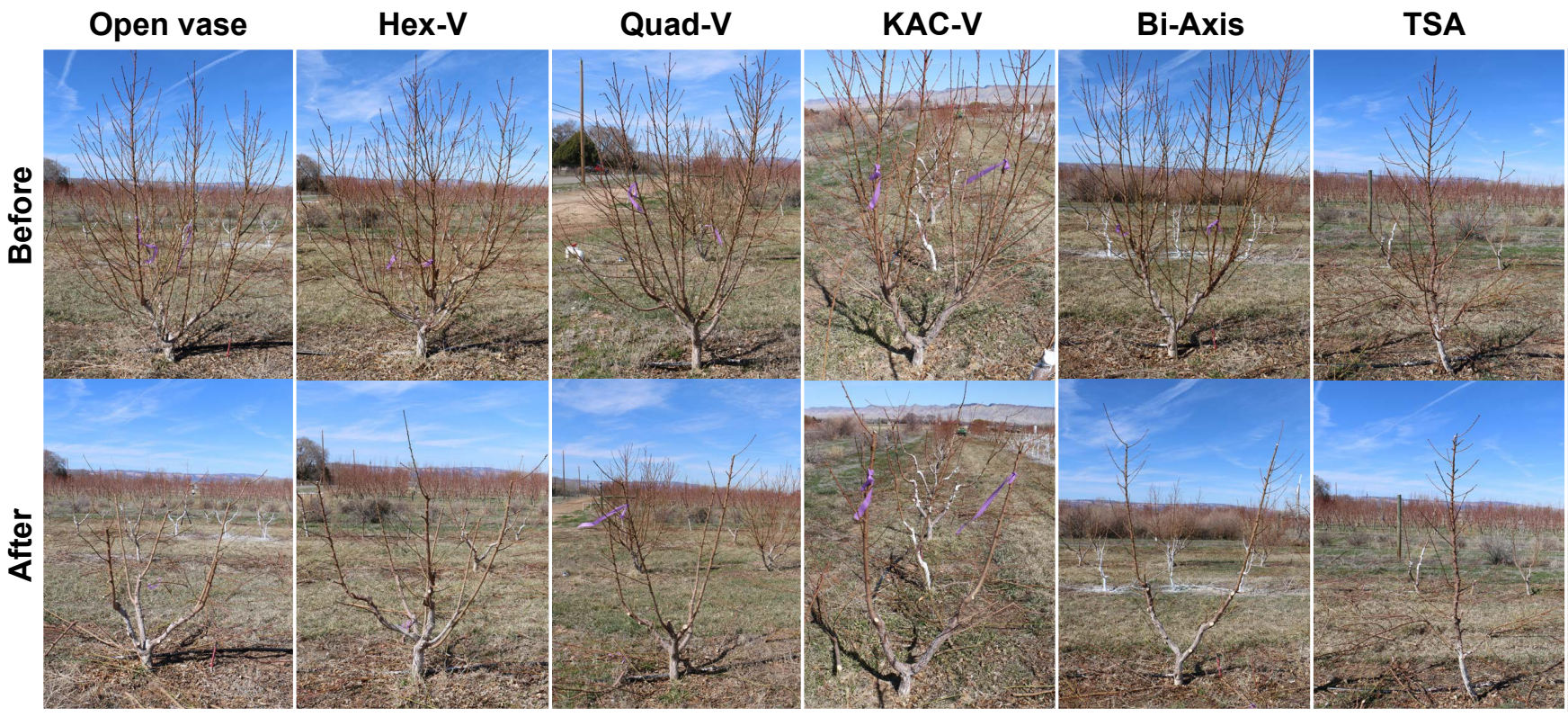

Figure 5. Orchard appearance of six canopy architectures of the most widely used training systems in 'O'Henry' peach trees (grafted on 'Krymsk ${ }^{\circledR} 86$ ' rootstock) before and after dormant pruning following the 3rd leaf from planting at the Colorado State University's Experimental Orchard at Western Colorado Research Center-Orchard Mesa (WCRC-OM) located in Grand Junction, CO, USA.

The open nature of this system can facilitate proper illumination to most areas in the canopy, but watersprouts and vigorous branches growing in the center of this $3 \mathrm{D}$ canopy can negatively impact fruit yields and quality. This canopy architecture does allow easy access to fruiting shoots for various management operations (e.g., pruning, thinning, harvesting), although typically requires ladders and can only facilitate lowdensity plantings of 600 trees ha $^{-1}$ or less [37]. Additional drawbacks to this system include the length of time needed to train these systems from planting to full production maturity (Figure 5), tree heights exceeding $4 \mathrm{~m}$ (hence the need for ladders) and the potential for excessive complex canopies [37]. For example, each open vase system maintains three to five primary scaffolds with two or three secondary scaffolds, and then an additional eight to 14 tertiary branches per each secondary scaffold, which can create a highly complex canopy (Figures 4 and 5) [39]. Increasing branches and/or growing points does not necessarily equals increased production, as light distribution needs to be considered for optimal yields and quality. Further, this complexity makes it difficult to increase labor efficiency, let alone the potential for mechanization of expensive orchard tasks [39]. However, when these systems are managed properly, they can produce large quantities of high-quality fruit [37].

\subsection{Medium-Density Systems}

Medium-density plantings are typically planted around $3.0 \times 4.5 \mathrm{~m}\left(600-1000\right.$ trees ha $\left.^{-1}\right)$ and reach approximate heights of $3.0 \mathrm{~m}$ (Table 2, Figure 4). These orchard systems were developed in an attempt to diffuse vigor, decrease tree height and reduce canopy complexity. As a result, alternative multi-leader systems were developed. These MDP multi-leader systems include the delayed vasette, Quad-V and Hex-V, while spindle systems such as the palmette represent single leader MDP systems. As a result of reduced tree heights 
and canopy complexity, trees can be planted at closer densities, achieving a larger number of trees and/or leaders per ha (Table 2). These MDP systems are a great compromise for growers who wish to maintain lower intensity management, while increasing land unit production without excessive orchard establishment costs.

\subsubsection{Delayed Vasette}

The delayed vasette is similar to an open vase system in terms of canopy architecture, but differs in how/when the scaffolds are developed. Similar to the open vase, the delayed vasette is developed with approximately four main scaffolds, originating at $50 \mathrm{~cm}$ above the ground. However, it differs in that the central leader is maintained in the center of the four main scaffolds for the first two to three years, in an attempt to distribute the vigor and encourage earlier fruiting production [19]. After two to three years, the central leader is completely removed, leaving behind a similar open vase structure, with four main scaffolds, with improved light penetration to the bottom portions of the canopy as the tree enters into maturity. This system is characterized by early bearing, high productivity and a mature architecture by year three or four [40]. The delayed vasette is a MDP solution for growers who wish to increase their planting densities to approximately 600-800 trees ha $^{-1}$ (Table 2, Figure 4), and yet maintain a similar open vase style canopy architecture [19].

\subsubsection{Palmette}

The palmette system is a very popular peach training system in central-northern Italy, where spring frosts are more frequent and require taller canopy architectures to minimize crop loss due to temperature inversions (i.e., radiative frost). The palmette system consists of a central leader with six or more branches inserted into the main stem at approximately 45-degree angles, with canopies reaching heights of four to five meters [19]. Given the height of these trees, ladders or platforms are required for orchard management tasks. Planting densities for the palmette system include 2.0-3.5 $\times 4.0-4.5 \mathrm{~m}$, achieving densities from 600-900 trees ha ${ }^{-1}$ (Table 2, Figure 4). Although, some authors believe these systems can be pushed towards higher densities, reaching 700-1100 trees ha ${ }^{-1}$ in peach [41]. The goal of the palmette system was to achieve a "true" fruiting wall, capable of inducing early yields and integrating the use of platforms for labor reduction and mechanization. The use of platforms for picking/pruning in the palmette system can simplify laborious tasks due to the planar and homogenous canopy architecture. If trees are planted too close, intra-tree shading can be a negative result, contributing to poor production and inferior peach fruit quality [41]. Therefore, the palmette system should be paired with the use of plant growth regulators, available semi-dwarfing rootstocks and low-vigor growing conditions to ensure uniform productivity, maturation and quality within the tree/orchard [41].

\subsubsection{Quad-V}

The Quad-V system developed by Day et al. [39,42] to further diffuse the vigor of higher-density two-leader systems such as the parallel and perpendicular V-systems (i.e., KAC-V) (Section 4.3.2), along with reducing orchard establishment costs by reducing the number of trees required to achieve the same number of leaders per acre [37]. This system mirrors the perpendicular V-system, but instead of a single pair of leaders extending over the inter-row, two sets of two-primary scaffolds are present (Figures 4 and 5). The Quad-V system ensured the same high yields, high light interception and canopy uniformity as the HDP system, KAC-V, while reducing the number of trees required at planting. Further, the Quad-V simplified the architecture of an open vase system (LDP), promoting a compromise between the KAC-V and open vase systems [37,39]. Typical planting densities for Quad-V systems range from $4.5 \mathrm{~m}$ in the inter-row to $2.5-3.0$ in the intra-row (900-1000 trees ha ${ }^{-1}$; Table 2, Figure 4). Given the number of scaffolds diffusing the vigor of the tree, tree heights will typically be lower, especially if the angle of the scaffolds is bent more towards the horizontal. However, wider angles may produce increased watersprouts in the central portion of the canopy and require extensive summer pruning [39]. Overall, the Quad-V 
system became very popular in California and remains an optimal balance between LDP, open vase and HDP, KAC-V systems [39].

\subsubsection{Hex-V}

The Hex-V is a further compromise for growers wishing to maintain lower-density plantings as a way to avoid expensive establishment costs, as Hex-V systems are typically planted at lower densities than the Quad-V. Hex-V orchards can maintain approximately 750 trees $\mathrm{ha}^{-1}$ and are planted at densities approximately $3.0 \mathrm{~m} \times 4.5 \mathrm{~m}$ (Table 2, Figure 4). The Hex-V system can either be developed with six primary scaffolds that are oriented with three scaffolds on either side of the alleyway, or with three primary scaffolds, which develop two secondary scaffolds each in a similar manner to an open vase system (Figures 4 and 5). The contrast between the open vase and the Hex-V is that the secondary scaffolds in the Hex-V do not continue to fork and promote tertiary branches. Only small fruiting shoots are developed along the scaffolds, allowing enhanced canopy uniformity, optimal light distribution and high light interception [37]. The benefit of shifting from the Quad-V (four scaffolds) to the Hex-V (six scaffolds) is that the increased number of leaders further help diffuse the tree/rootstock vigor to promote smaller canopies ( $<2.5 \mathrm{~m}$ in height). This results in trees that can be managed more easily and in some cases without ladders, given the further reduction in tree height (Table 2, Figures 4 and 5).

\subsection{High-Density Planting Systems}

High-density planting systems are typically planted around $1.5 \times 4.0 \mathrm{~m}$ (1000-2000 trees $\mathrm{ha}^{-1}$ ) and reach heights ranging 3.0-5.5 $\mathrm{m}$ (Table 2, Figure 4). Training systems used in HDPs, such as the central leader iterations (Fusetto, Tall Spindle Axe, Slender Spindle Axe) and Y-systems maximize land area production and light interception, while maintaining light distribution throughout the canopy. This allows for higher crop loads, which may reduce fruit size, but allows for improved SSC, DMC, color, and overall quality, due to improved light characteristics in the tree. The up-front cost for the higher number of trees and potential trellising may be a potential financial barrier of entry for growers, but these costs may be recouped quickly due to increased precocity and early yields obtained in these systems. Furthermore, HDPs may require more intensive management and horticultural knowledge, but the simple design may allow for the potential of mechanization, platforms and robotics to reduce labor time/costs. Some examples of intensive management and horticultural knowledge necessary in HDP systems include the use of plant growth regulators (PGRs) (e.g., gibberellin-inhibitors) and size-controlling rootstocks.

\subsubsection{Central Leader Systems (Fusetto, Tall Spindle Axe, Slender Spindle Axe)}

The Fusetto system is an Italian adaption of the slender spindle axe (SSA) system, which is widely popular in apple production. The Fusetto system is a central leader system, which develops seven to eight branches originating from the main axis [19]. On average, the Fusetto system is planted at spacings of $2.0 \times 4.0 \mathrm{~m}\left(\sim 1250\right.$ trees ha $\left.{ }^{-1}\right)$, although densities may vary based on soil, climate and growing conditions (Table 2$)$. Trees are grown to heights of 2.8-3.5 m, ensuring not to exceed the inter-row spacing (Table 2, Figure 4). In contrast, the Tall Spindle Axe (TSA) is typically grown to taller heights (3.0-3.7 m), although the TSA retains a similar canopy architecture to the Fusetto. Both the Fusetto and TSA are trained in a conical fashion, with larger, more dominant branches in the basal portion of the tree, while branches recede in size as they reach the apex portion of the canopy [19]. The shape of this system allows branches at the basal portion of the canopy to extend further into the inter-row in order to maintain high levels of light interception and subsequent production in the bottom of the canopy (Figures 4 and 5). However, these canopies can often be too large in respect to volume (i.e., high leaf area/density), leaving internal and/or bottom portions of the canopy with excessive shade and poor fruit quality and production. Therefore, the use of size-controlling rootstocks, PGRs, summer pruning, watersprout 
removal and reflective fabrics on these higher density systems may be advised to ensure optimal light interception, penetration and distribution values.

\subsubsection{Y-Shaped Systems (Tatura Trellis, KAC-V, Bi-Axis)}

The perpendicular-V or Y-shaped systems are characterized by two scaffolds that extend over the inter-row (i.e., tractor alleyway) with fruiting shoots grown on the exterior in a "herringbone" pattern (Figure 4), with shoot renewal occurring with each season [19]. The goal behind the development of these trees was to increase planting densities and increase light interception, by maximizing light in the interior of the canopy at solar noon. The original Y-system was the Tatura trellis, which was developed in Australia [43]. In the following years, many iterations of these Y-shaped systems were developed, with different angles and densities utilized [19]. One of the most popular iterations was the KAC-V system (Figure 5), which was developed at UC Davis, in California, in 1982 as a hybrid of the traditional open vase system and the Tatura trellis [44].

The criteria for the development of the KAC-V were to: increase production in the early years after planting, maintain yields similar to open vase systems, reduce the need for summer pruning, maintain similar row spacings for tractors, increase the labor use efficiency for various orchard tasks (e.g., pruning, thinning and harvesting) and increase light use efficiency [44]. The two leaders are selected in the first year, while the use of summer and dormant pruning to remove competing branches is conducted to ensure a simplified canopy (Figure 5). Long fruiting shoots are not to be perennial, but rather shoot renewal is conducted each year during the dormant season to adjust for an appropriate crop load by leaving the associated number of "hangers" left on the tree to fruit (1-2 fruit/hanger; i.e., fruiting shoot) [44]. One major benefit of the KAC-V system is the lack of trellis requirement, as these scaffolds are developed to be strong and free-standing. However, one major drawback of this system is the frequent need for summer pruning (two-three times a season) in the internal/basal portion of the canopy, where the development of watersprouts / suckers are highly prevalent (Figure 5) [19]. Therefore, the use of watersprout removal (WSR) is advised to ensure proper illumination in the dorsal/internal portions of the canopy. Strong heading cuts on these watersprouts (leaving $15 \mathrm{~cm}$ ) should be made instead of complete thinning cuts to provide a small amount of leaf area/shade to prevent sunburn on the scaffolds [44]. These headed shoots can then be completely removed in the dormant season. Lastly, given the perpendicular orientation of the KAC-V, it is difficult to mechanize tasks parallel with the tractor row, as well as in the internal portions of the canopy. In sum, the KAC-V system reduces the complexity of the open vase system, arranges the canopy and fruiting shoots into manageable functional units to better manage crop load, intercepts high amounts of light and achieves higher densities of $\sim 1000$ trees $\mathrm{ha}^{-1}$ [44].

The Bi-Axis is a similar Y-shaped system but it maintains two leaders in the parallel direction of the row and can therefore create a homogenous, continuous fruiting wall (Figure 5). The Bi-Axis is a combination of the KAC-V and the Fusetto. The Bi-Axis can be planted at high densities (>2000 trees ha ${ }^{-1}$ ), but it can also achieve and/or increase the total number of leaders per hectare with less trees (Table 2, Figure 4). This is a major benefit for growers wishing to reduce upfront orchard establishment costs. The Bi-Axis systems, with high planting densities, achieve high light interception values, but also prioritizes uniform light distribution and high light penetration as these canopies are managed to be quite narrow (70-90 cm in depth). A primary advantage of all Y-shaped systems is the ability to diffuse tree vigor into two leaders, which can help minimize tree height and maximize labor efficiency, when compared to single-leader HDPs (Table 2, Figure 4). This is especially true with the Bi-Axis system, while the KAC-V is typically managed more like an open vase system achieving much taller tree heights to maximize production on the two leaders (Figure 5). In sum, the Bi-Axis orients the two primary scaffolds parallel to the row orientation in order to optimize light relations in the tree, promote the development of thin canopies and integrate the use of mechanization and/or robotics to reduce labor costs. 


\subsubsection{Cordon Systems}

Cordon systems have been developed and implemented in several other tree fruit species, such as the cherry UFO (or Bi-UFO) and the apple Super-Vee [25,45-47]. Cordon systems have been developed for peach production systems as well to achieve uniform canopy shapes, induce high early yields and potentially reduce the need for ladders $[37,48]$. Cordon systems are typically developed with one or two leaders that are bent towards the horizontal after the first growing season. In trials, this system has been planted at a density of $2.4 \times 4.0 \mathrm{~m}\left(919\right.$ trees ha $\left.{ }^{-1}\right)$ and kept under 2.5 in height [48] (Table 2). In respect to the Cordon (aka "Salter") system, which was initially developed in California for peach [49], the trees are left to grow vigorously in the first year, until two dominant leaders can be selected for [48]. These leaders are then left in the horizontal position approximately $1.0-1.5 \mathrm{~m}$ above the ground and act as "cordons", in which upright growing fruiting shoots emanate from $[48,50]$. However, it has been noted that trying to fruit on vigorous uprights is difficult in peach, unlike cherry, and so the system has been modified recently to develop short fruiting shoots on the semi-permanent upright scaffolds that originate from the cordon [50]. Several iterations of the cordon systems are now being developed in Spain, Greece and Colorado, USA (Minas Lab, Colorado State University), on vigorous and dwarfing rootstocks, experimenting with various numbers of uprights per cordon.

\subsection{Ultra High-Density Planting Systems}

The only UHDP training system evaluated includes the meadow orchard, which was initially developed for apple production. UHDPs were developed with the goal of inducing precocious early yields and enable complete mechanization of orchard tasks. Apart from mechanization, trees could be managed completely from the ground, not exceeding $2.2 \mathrm{~m}$ (Table 2). Meadow orchards, although interesting in theory, never fully took off in apple nor peach for various reasons, but it was primarily due to the excessive costs of orchard establishment given the large number of trees per hectare. UHDPs are typically planted around $0.5-1.0 \times 1.5-3.0 \mathrm{~m}$ on average, and can range from 2700 to greater than 10,000 trees ha ${ }^{-1}$ (Table 2).

\section{Meadow Orchards}

Meadow orchards were initially developed in England for apple production with the goal of creating an early cropping system that maintained uniform fruiting structures, canopy light distribution and the ability to be fully mechanized [51,52]. Meadow orchards are very dense plantings that cover the entire field within the first year and are completely pedestrian, maintaining heights below $2.2 \mathrm{~m}$ [53]. Meadow orchards can include plantings ranging from 2700 to 19,000 trees per hectare, with planting densities of $0.4-1.0 \times 1.3-4.8 \mathrm{~m}$ (Table 2). Meadow orchards are managed on a biennial cycle, cropping one portion of the orchard one year, while the other portion is completely pruned back and allowed to redevelop the canopy in the same year. These blocks would then alternate. Whichever portion was cropped in the first year is then pruned back, while the pruned portion would then be allowed to crop in the next year. However, the economics of a biennial system are not always desirable, so the use of early cultivars was suggested to condense this production system into one year [52]. In a condensed one-year cycle, vigorous early cultivars could crop early and then be headed back immediately after harvest, which would allow the entire canopy to rebuild and grow in the same season to crop again in the subsequent year [52]. Overall, the goal of this system is to maintain young one-year-old fruiting wood only and reduce the size and number of large permanent scaffolds, along with their potential to contribute to intra-tree shading [53]. With a lack of dwarfing rootstocks, the use of intensive annual pruning could help control tree vigor. The systems' propensity to crop on one-year-old wood was why it was not largely adopted in apple, as only selected apple cultivars can bear on one-year old wood. In peach, this issue is ameliorated and therefore the meadow orchard system could be potentially more effective for peach 
producers [52]. However, given the large number of trees planted at establishment, the meadow orchard system failed to be fully commercially adopted in peach as well, due to excessive start-up costs [53].

\section{Impact of Training Systems on Light Relations, Production and Fruit Quality}

While several systems and various iterations of each exist, there are primary guiding principles and objectives each training system is trying to achieve. Generally, these include improving light relations (interception, distribution and penetration), increasing production, allowing easier thinning and harvesting, and enhancing fruit quality.

\subsection{Training Systems and Light Relations}

A linear relationship exists between light interception and yield [54]. Light interception (LI) can be increased through two ways: (1) increasing the canopy leaf density, which limits light distribution within the tree, and (2) increasing the leaf area index (LAI; leaf area:ground area), which is accomplished by planting a higher number of smaller trees per hectare (i.e., planting density) [30]. The second strategy is optimal to ensure uniformly illuminated canopies. However, LI is only linearly correlated with yields up to about $50-60 \%$ of light interception $[29,55]$. At this point, with increased LAIs, other factors must be considered, such as light distribution. Hence, shifting to a higher number of narrower/thinner canopies, facilitated by simple 2D training systems (grafted on size controlling rootstocks), helps encourage both high light interception and high light distribution throughout the entirety of the canopy. Both of these parameters are important, as increased light throughout the totality of the canopy allows for increased total flower bud initiation, yields and uniform high-quality fruit, which can reduce the number of picks and labor cost at harvest. However, if plantings are too dense, increased shading can cause vegetative imbalances within the tree and can negatively impact fruit quality and induce tree decline more rapidly [56]. These density thresholds for optimal light, yield and economics have been well established for apple (2600-3000 trees ha $\left.{ }^{-1}\right)$ [26,56-58], but remain undetermined in peach.

While density plays a primary role in maximizing light interception, the training system and canopy architecture also influence how the incident light is intercepted and distributed. For example, open vase and other multi-leader or Y-shaped systems that share this similar shape (i.e., Hex-V, Quad-V, KAC-V, etc.), can maintain a higher level of light interception at solar noon, given their open and receptive shape. While planar systems such as the cordon or palmette systems have to heavily rely on the morning or late-afternoon light for photosynthesis, due to the lower amount of light intercepted at mid-day [56]. In a training system trial comparing delayed vasette (DV), palmette (P) and Y-trellis (Y) in peach, DV and P intercepted a similar amount, while the Y-system intercepted the highest amount of light [59]. Further, whole canopy photosynthesis was linearly related to light interception, with increased levels of photosynthesis occurring in the Y-system when compared to the DV and P system [59]. Similarly, a cordon system along with a higher-density version of the KAC-V (HiD KAC-V), intercepted the highest amount of light when compared to an open vase system [29]. This contributed to increased levels of fruit number per ground area and fruit dry mass per ground area in these HDP systems, when compared to the open vase [29].

When evaluating the impacts of density versus training system on light use efficiency in apple, Robinson et al. [60] noted the highest amount of light-conversion efficiency (i.e., assimilates for the fruit) was observed not in the highest density planting, but rather in the system that intercepted the optimal levels of light $(69 \%)$, whereas in respect to maximum yield efficiency $\left(\mathrm{kg} \mathrm{cm}^{-2}\right)$, the highest density system reached the highest levels, rather than the reduced planting densities with more optimal light thresholds [60]. In other words, if maximum yields are the goal, planting the highest number of trees is the best way to do it. Although, profitability and the cost of establishment/management must be considered, along with the quality of the fruit produced. This trend was true in a 
previous peach training systems trial evaluating open vase $\left(299\right.$ trees $\left.\mathrm{ha}^{-1}\right)$, cordon system (919 trees ha $\left.{ }^{-1}\right), K^{\prime}$ AC-V (919 trees ha ${ }^{-1}$ ) and HiD KAC-V (1196 trees ha ${ }^{-1}$ ), where yields were the highest in the HiD KAC-V and the lowest in the open vase [29]. However, as mentioned previously, planting densities at excessive levels can negatively impact fruit quality and can deteriorate the life span of the orchard. Simply put, the highest quality potential for fruit in an orchard is reached well before maximum yields are met [56]. Therefore, optimal densities and proper training system architecture is critical to ensure a balance of both high yields and high fruit quality.

The ideal combination for orchard design, training system selection and planting density is going to vary from farm to farm based on soil type, climate, cultivar and rootstock selections, management techniques and economics [36]. However, the guiding principle should be to reach light interception values of $60-70 \%$, while maintaining uniform light distribution (vertically) and penetration (depth) through the canopy without increasing the vegetative growth potential $[29,55]$. In general, two main strategies have been adopted to achieve these objectives in a high-density context: (1) the planting of central axis conical trees (i.e., SSA, TSA, Fusetto, etc.) with narrow inter-row and intra-row spacings, and (2) the planting of Y-shaped, cylindrical Tatura trellis iterations, in close intra-row spacings to form slanted fruiting walls along the tractor alleyways [20]. Overall, these orchard design systems have displayed increased photosynthetic, water use and yield efficiencies [20].

\subsection{Training Systems and Productivity}

High density plantings increase light interception and subsequent yield potentials. Yield efficiency can increase with an increased number of trees per hectare [26], but assimilation to fruit can diminish as shade avoidance strategies are induced, prioritizing vegetative growth and negatively influencing fruit quality. This is why DeJong and Grossman [29] have suggested that training system selection is equally about optimizing light interception while reducing the vegetative growth potential of the trees. For example, although cordon systems facilitate increased densities, light interception and assimilate production, the way they are trained and heavily pruned to maintain upright scaffolds induces a lot of vegetative growth [29]. As a result, although the cordon system intercepted a high amount of light in a previous study, it partitioned a high amount of photosynthates to vegetative sinks and resulted in the lowest harvest index (ratio of fruit dry mass:sum of fruit, leaf and stem dry mass) when compared to the KAC-V, HiD KAC-V and open vase systems [29]. Overall, the cordon system was the least efficient system in respect to crop production in this trial, but it was still more economically efficient than the open vase, as this LDP system sustains minimal yields given the low number of trees per hectare.

In a recent study evaluating open vase $\left(571\right.$ trees ha $\left.^{-1}\right)$, Y-shaped (1333 trees ha ${ }^{-1}$ ) and central leader $\left(2500\right.$ trees ha $^{-1}$ ) systems in Brazil, it was demonstrated that the central leader maintained the smallest canopy volume $\left(\mathrm{m}^{3}\right)$, yielded the least number of fruits per tree, but given the higher planting density, produced the most on a per hectare basis $\left(\mathrm{Mt} \mathrm{ha}^{-1}\right)$ [61]. A similar trial revealed that after four years, a V-system (i.e., Tatura trellis, Y-shaped) yielded the most on a cumulative basis (1388 trees ha $\left.{ }^{-1}, 80.1 \mathrm{Mt} \mathrm{ha}^{-1}\right)$, followed by a central leader/spindle (1388 trees ha $\left.{ }^{-1}, 66.1 \mathrm{Mt} \mathrm{ha}^{-1}\right)$ and then a bush system (i.e., open vase) (606 trees ha ${ }^{-1}, 47.7 \mathrm{Mt} \mathrm{ha}^{-1}$ ) [62]. The authors suggest that the diffusion of vigor in the $\mathrm{V}$ (two leaders) vs. the single leader encourages less vegetative growth and subsequent pruning, which maintains a better reproductive balance and increased yields over time [62]. However, this is only true for a mature V- or Y-system, as extensive pruning and training is required in the first two years to develop the scaffolds (Figure 5), while this is not required in the central leader systems [63]. Regardless, given the need for a trellis in the spindle system, the $\mathrm{V}$ was noted as a more cost-effective system given the increased production and reduced establishment/infrastructure costs [62]. In a contrasting study, a central leader system yielded more fruit than a Y-system, but the central leader demonstrated smaller fruit size [63]. Unfortunately, the planting densities and crop loads were not given, so it is difficult to ascertain whether these training system impacts on yield 
were an artifact of different plantings and/or crop loads [63]. In respect to Y-systems, it has been demonstrated that they can develop a larger percentage of fruiting shoots per plant dry weight than central leader trees [64]. Overall, HDP systems tend to produce more on a per unit land-area basis than LDP/MDP systems, even while minor nuances may exist between specific HDP training systems in respect to production. Further, Y-systems have demonstrated an effective ability to produce high yields early on, helping to recoup high orchard establishment costs. However, these yield and profitability gaps between HDP and MDP systems may diminish over time ( 12 years) as trees mature, maximum yield thresholds are met and less labor/costs are required in lower density plantings [65].

Profitability in HDP systems can remain high, if high quality thresholds are met. That is to say that the economic returns of these systems are highly dependent on the farmgate price, or crop value, in a particular season [50]. This underscores the significance of prioritizing fruit quality in orchard design and training system selections. If quality and crop value is not properly developed in the orchard, nor maintained postharvest, the advantages of high-density systems will be negated. Therefore, to ensure maximum economic returns and HDP success, fruit quality must be prioritized.

\subsection{Training Systems and Fruit Quality}

Maximizing fruit quality begins in the field and can be achieved through the manipulation of canopy architecture to enhance light relations within the tree. Peach fruit size, overcolor, SSC and DMC positively correlate with increased light interception/availability $[30,54]$. Therefore, to elicit exceptional quality, the goal of a training system should be to optimize light interception and distribution.

Training systems influence the canopy shape, depth and size of the tree, which impacts the spatial distribution of fruit in the tree and their quality characteristics $[33,66]$. A study comparing a delayed vasette (DV) and a perpendicular-Y $(Y)$ system demonstrated that the highest number of fruit and yield was in the middle portion of the canopy, regardless of the system, although the $\mathrm{Y}$ had a more uniform distribution of fruit across the tree [66]. Fruit weight decreased from the top to the bottom in the DV, while in the $\mathrm{Y}$, fruit weight remained stable across the canopy [66]. This was perhaps due to the increased uniformity of light distribution across the Y-system and is also supported with more uniform red coloration in the $\mathrm{Y}$, when compared to the DV as well [66]. Similar to fruit weight trends, fruit SSC and coloration decreases from the top to the bottom of the canopy, with decreasing light availability $[33,65,67]$. An additional experiment evaluating a Y-system and a central leader revealed that the Y-system yielded more uniform fruit quality, pigmentation and size from the top to the bottom, when compared with the central leader [65]. It was hypothesized that the improved quality and yield efficiency of the Y-system in this study was due to the enhanced spatial distribution of the canopy and reduced leaf density, which contributed to increased light use efficiency $[65,68]$. In sum, these experiments demonstrate that uniform canopies with even light distribution generate uniform fruit quality, and that fruit quality is more indicative of the environment the fruit experiences throughout development rather than the canopy position alone $[69,70]$. Therefore, training system selection and development should focus on creating thin canopies, whether planar or open, in an attempt to ensure proper illumination to all portions of the canopy.

As planting densities increase, the leaf area index on an orchard scale increases (LAIorchard, $\mathrm{m}^{2} \mathrm{~m}^{-2}$ ), as trees cover more of the orchard floor. However, it is critical that while LAI-orchard is increasing, LAI on a tree scale (LAI-tree, $\mathrm{m}^{2} \mathrm{~m}^{-3}$ ) should remain stable or decrease [71], as tree size is reduced through the facilitation of dwarfing rootstocks [20]. Peach trees grafted on size-controlling rootstocks, with limited canopy leaf density (i.e., LAI-tree) will promote high fruit quality, in respect to size, color, SSC and DMC [9,20], while inversely, if LAI-tree reaches excessive thresholds due to a lack of dwarfing rootstocks, highly fertile soils or improper planting densities, fruit quality and production will be impaired as shade develops. In peach, the photosynthetic activity of shaded leaves is less than $10 \%$ of leaves fully exposed to the sun [72]. As a result, shade negatively impacts the 
amount of photosynthates exported to the fruit for quality development, along with floral bud induction for production in the subsequent year. Therefore, training system selection can help re-arrange the canopy architecture of trees with vigorous rootstocks and/or soils to create thinner/more sun-exposed canopies.

To manage a high-vigor situation, training systems that diffuse vigor into multiple leaders may be selected (e.g., Y-shaped, KAC-V, Bi-Axis) or training systems that facilitate fruiting walls with taller tree heights (e.g., Palmette, TSA). Increased tree heights require increased inter-row spacings as to not project shade on the proximate rows in the morning and late afternoon. Additionally, summer pruning applications (or WSR) to control for vigor and maintain well-exposed canopies may also be required. Thus, planar training systems would be ideal to facilitate the mechanization of this task. Deficit irrigation may be another management practice that could be equipped to high-density plantings to reduce excessive vegetative growth and intra-tree shading for high fruit quality [19]. Smaller trees and planar training systems are more efficient in respect to light, water and yield efficiency, which allows for a more balanced tree and improved photosynthate resources for developing fruits to obtain higher quality at harvest. The selection of an ideal training system and orchard design will be largely contextualized to the environmental and economic conditions of the farm, but should seek to create thin, exposed and uniform canopies for consistent yields of high-quality fruit.

Lastly, when optimizing canopy architecture for optimal light and quality thresholds, fruit maturation must also be considered. Increased light advances peach maturation, which subsequently improves quality. So, any true evaluation on the impact of training systems on fruit quality, must control for maturity [3].

Controlling for Confounding Variables to Elicit the True Impact of Preharvest Factors on Peach Fruit Quality

Maturity control has been the focus of several recent pomological experiments investigating the role preharvest factors have on peach fruit quality and metabolism [12,70]. Maturity control can be achieved through the use of Vis-NIRS technology that can evaluate $\mathrm{I}_{\mathrm{AD}}$ and DMC simultaneously in a single scan [9]. Trees planted in HDPs on dwarfing rootstocks tend to be highly precocious and set high crop loads, which can negatively impact fruit quality [12]. In general, HDPs have demonstrated reduced fruit weight (perhaps due to unregulated high crop loads), but have compensated for this with improved coloration and internal quality parameters, such as SSC and DMC, due to increased light interception and photosynthetic efficiency [3]. Therefore, crop load is another confounding variable such as maturity status that must also be controlled for (no. of fruit $\mathrm{cm}^{-2}$ of TCSA, no. of fruit $\mathrm{m}^{-3}$ of canopy volume, etc.) across training systems to ensure fair comparisons of their impact on quality.

In further respect to the role crop load has on peach fruit quality, it was determined that fruit from a thinned, carbon sufficient, treatment demonstrated increased fruit size, weight, SSC and DMC, when compared to an unthinned, carbon starved, treatment, even when controlling for maturity [12]. This experiment demonstrated the true impact of carbon supply on peach fruit quality.

Further, this maturity control approach elicited the capacity to investigate the biological impacts of carbon supply, such as the metabolome. This study showcased that early metabolic shifts play a role in priming the quality phenotype at harvest [12]. Metabolite profiles were widely distinct early in development, when phenotypes were similar between the carbon starved and sufficient treatments. However, at harvest, metabolite profiles were fairly similar due to maturity control and the regulation of the primary metabolism by maturation, while quality phenotypes were widely distinct [12]. In particular, catechin maintained significantly higher levels in the carbon sufficient treatment throughout development, when compared to the carbon starved treatment, and demonstrated strong linear relationships with DMC and SSC at harvest [12].

An additional experiment showcased that fruit quality differences across canopy positions are largely due to variable light environments [70]. Quality (i.e., DMC) was 
significantly different between canopy positions (e.g., top vs. bottom) in two cultivars of variable vigor (low vs. high), prior to maturity control [70]. However, after maturity was controlled for between positions in each cultivar, quality differences only remained in the high-vigor cultivar, where light distribution was non-uniform [70]. As a result, when investigating the metabolite profiles across these environments, metabolite profiles in the exocarp were highly variable in the high-vigor cultivar between positions, while profiles were similar in the low-vigor cultivar [70]. Further, two compounds serve as metabolic signatures of the light environment. Sorbitol and citric acid demonstrated similar abundances across canopy positions in the low-vigor cultivar (with uniform light), while in the high-vigor cultivar (non-uniform light) these compounds were significantly different across positions [70]. Sorbitol was up-accumulated in the top position and a signature of high-quality, while citric acid was elevated in the bottom position and an indicator of inferior fruit quality [70]. In short, canopies with uniform light distribution will elicit uniform quality and metabolite profiles at harvest, when maturity is controlled for [70].

Lastly, when evaluating the role of rootstock vigor on peach fruit quality, a recent study was conducted, controlling both for crop load and maturity status of the fruit [27]. The results demonstrated a relationship between quality, vigor and light availability. With increasing rootstock vigor, light availability in the fruit zone (1.5 $\mathrm{m}$ above ground) decreased along with fruit DMC [27]. Dwarfing rootstocks modified the canopy architecture to increase light availability within the canopy to enhance peach fruit quality at harvest [27]. When confounding variables such as crop load and maturity status are controlled for, the true impact of these preharvest factors (e.g., crop load, canopy position and rootstock) can be determined. In sum, enhanced carbon supply improves quality, uniform canopies produce uniform quality and dwarfing rootstocks improve light in the canopy for increased DMC accumulation $[12,27,70]$.

\section{Conclusions}

Peach production remains a significant industry in the global agricultural economy. However, peach consumption is in decline due to poor fruit quality, threatening the profitability and sustainability of the peach industry. Therefore, optimizing management for high fruit quality must be the focus of peach production, as consumers are willing to pay more for a superior product. Fruit quality can only be developed in the orchard through optimizing preharvest factors, such as orchard design and training systems. With the development of dwarfing rootstocks and vigor diffusion training systems comes the opportunity for peach production to transition, such as apple and cherry, to high-density planting systems to maximize land use efficiency, light, yields and fruit quality.

Several training systems have been developed over recent decades to improve economic, resource and labor characteristics of peach production. Historically, LDP training systems such as the open vase has been and continues to be widely used given a lack of dwarfing rootstocks and its ease of management. However, LDP systems do not achieve maximum light, yield nor quality potentials in an orchard. Now, with the increasing availability of dwarfing rootstocks, higher-density plantings have been pursued. However, when size-controlling rootstocks are not available, multi-leader systems (or cordons with several uprights) can be used to diffuse vigor horticulturally. In the pursuit of increased densities, MDP systems have been developed, such as the delayed vasette, palmette, Quad$\mathrm{V}$ and Hex-V. The goal of MDP systems include: increasing light interception, increasing yields and reducing tree heights. Unfortunately, the complex 3D architecture of these LDP and MDP systems limit light distribution and can promote intra-tree shading. HDPs such as the Fusetto, TSA and Tatura trellis (and its iterations) have been developed to further increase yields and quality across the totality of the canopy, as light distribution is a key objective with these systems. These HDP training systems can generate homogenous fruiting walls to promote the use of mechanization/robotics to reduce labor costs.

The ideal system will vary from farm to farm, but the overall goal of training system selection and orchard design should be: (1) to optimize light interception (60-70\%) and 
yields, (2) promote thin canopies $(70-90 \mathrm{~cm})$ with reduced leaf density for high light distribution and enhanced/uniform fruit quality and (3) find a balance between maximum yield potential and maximum fruit quality potential.

Author Contributions: Conceptualization, B.M.A. and I.S.M.; software, B.M.A. and I.S.M.; investigation, B.M.A. and I.S.M.; resources, I.S.M.; writing-original draft preparation, B.M.A. and I.S.M.; writing-review and editing, B.M.A. and I.S.M.; visualization, B.M.A. and I.S.M.; supervision, I.S.M.; funding acquisition, I.S.M. All authors have read and agreed to the published version of the manuscript.

Funding: The present article was supported by the Specialty Crop Block Grant Program of the U.S. Department of Agriculture (USDA) in cooperation with the Colorado Department of Agriculture (CDA) and the project \#20202690 'Management strategies to maximize Colorado peach orchards productivity and fruit quality potential'. Its contents are solely the responsibility of the authors and do not necessarily represent the official views of the USDA or CDA.

Institutional Review Board Statement: Not applicable.

Informed Consent Statement: Not applicable.

Data Availability Statement: Not applicable.

Conflicts of Interest: The authors declare no conflict of interest.

\section{References}

1. FAO. FAOSTAT. 2019. Available online: http://www.fao.org/faostat/en/\#home (accessed on 31 July 2021).

2. USDA-National Agricultural Statistics Service. 2019. Available online: http://www.nass.usda.gov/ (accessed on 31 July 2021).

3. Minas, I.S.; Tanou, G.; Molassiotis, A. Environmental and orchard bases of peach fruit quality. Sci. Hortic. 2018, 235, 307-322. [CrossRef]

4. Crisosto, C.H.; Labavitch, J.M. Developing a quantitative method to evaluate peach (Prunus persica) flesh mealiness. Postharvest Biol. Technol. 2002, 25, 151-158. [CrossRef]

5. Crisosto, C.H.; Costa, G. Preharvest factors affecting peach quality. In The Peach: Botany, Production and Uses; CABI: Cambridge, MA, USA, 2008; pp. 536-549.

6. Crisosto, C.H.; Crisosto, G.M. Relationship between ripe soluble solids concentration (RSSC) and consumer acceptance of high and low acid melting flesh peach and nectarine (Prunus persica (L.) Batsch) cultivars. Postharvest Biol. Technol. 2005, 38, 239-246. [CrossRef]

7. Testoni, A. Momento di raccolta, qualita, condizionamento e confezionamento delle pesche. In Proceedings of the Symposium La Peschicoltura Veronese Alle Soglie Del, Verona, Italy, 25 February 1995; pp. 327-354.

8. Hilaire, C. The peach industry in France: State of art, research and development. In Proceedings of the First Mediterranean Peach Symposium, Agrigento, Italy, 10 September 2003; pp. 27-34.

9. Minas, I.S.; Blanco-Cipollone, F.; Sterle, D. Accurate non-destructive prediction of peach fruit internal quality and physiological maturity with a single scan using near infrared spectroscopy. Food Chem. 2021, 335, 127626. [CrossRef]

10. Serra, S.; Anthony, B.; Masia, A.; Giovannini, D.; Musacchi, S. Determination of Biochemical Composition in Peach (Prunus persica L. Batsch) Accessions Characterized by Different Flesh Color and Textural Typologies. Foods 2020, 9, 1452. [CrossRef]

11. Giovannoni, J.; Nguyen, C.; Ampofo, B.; Zhong, S.; Fei, Z. The epigenome and transcriptional dynamics of fruit ripening. Annu. Rev. Plant Bio. 2017, 68, 61-84. [CrossRef]

12. Anthony, B.M.; Chaparro, J.M.; Prenni, J.E.; Minas, I.S. Early metabolic priming under differing carbon sufficiency conditions influences peach fruit quality development. Plant Physiol. Biochem. 2020, 157, 416-431. [CrossRef]

13. Ziosi, V.; Noferini, M.; Fiori, G.; Tadiello, A.; Trainotti, L.; Casadoro, G.; Costa, G. A new index based on vis spectroscopy to characterize the progression of ripening in peach fruit. Postharvest Biol. Technol. 2008, 49, 319-329. [CrossRef]

14. Costa, G.; Noferini, M.; Fiori, G.; Torrigiani, P. Use of Vis/NIR spectroscopy to assess fruit ripening stage and improve management in post-harvest chain. Fresh Prod. 2009, 1, 35-41.

15. Reighard, G.L.; Loreti, F. Rootstock development. In The Peach: Botany, Production and Uses; Layne, D.R., Bassi, D., Eds.; CABI: Cambridge, MA, USA, 2008; pp. 193-220.

16. Layne, R.E.C. Peach rootstocks. In Rootstocks for Fruit Crops; Rom, R.C., Carlson, R.F., Eds.; Wiley: Hoboken, NJ, USA, 1987.

17. Reighard, G.; Bridges, J.W.; Archbold, D.; Wolfe, D.; Atucha, A.; Pokharel, R.; Autio, W.; Beckman, T.; Black, B.; Lindstrom, T.; et al. NC-140 Peach Rootstock Testing in Thirteen U.S. states. Acta Hortic. 2015, 225-232. [CrossRef]

18. Reighard, G.L.; Bridges, J.W.; Archbold, D.; Atucha, A.; Autio, W.; Beckman, T.; Black, B.; Chavez, D.J.; Coneva, E.; Day, K.; et al. Nine-year rootstock performance of the NC-140 'Redhaven' peach trial across 13 states. J. Am. Pomol. Soc. 2020, 74, 45-56.

19. Loreti, F.; Massai, R. The High Density Peach Planting System: Present Status and Perspectives. Acta Hortic. 2002, 377-390. [CrossRef] 
20. Loreti, F.; Massai, R. State of the Art on Peach Rootstocks and Orchard Systems. Acta Hortic. 2006, 253-268. [CrossRef]

21. Perry, R.; Reighard, G.; Ferree, D.; Barden, J.; Beckman, T.; Brown, G.; Cummins, J.; Durner, E.; Johnson, S.; Layne, R.; et al. Performance of the 1984 NC-140 cooperative peach rootstock planting. J. Am. Pomol. Soc. 2000, 54, 6-10.

22. Autio, W.; Robinson, T.; Black, B.; Blatt, S.; Cochran, D.; Cowgill, W.; Hampson, C.; Hoover, E.; Lang, G.; Miller, D.; et al. Budagovsky, Geneva, Pillnitz, and Malling apple rootstocks affect 'Hon-eycrisp' performance over the first five years of the 2010 NC-140 'Honeycrisp' Apple Rootstock Trials. J. Am. Pomol. Soc. 2017, 71, 149-166.

23. Autio, W.; Robinson, T.; Blatt, S.; Cochran, D.; Francescato, P.; Hoover, E.; Kushad, M.; Lang, G.; Lordan, J.; Miller, D.; et al. Budagovsky, Geneva, Pillnitz, and Malling apple rootstocks affect 'Honeycrisp' performance over eight years in the 2010 NC-140 'Honeycrisp' apple rootstock trial. J. Am. Pomol. Soc. 2020, 74, 182-195.

24. Musacchi, S.; Gagliardi, F.; Serra, S. New Training Systems for High-density Planting of Sweet Cherry. HortScience 2015, 50, 59-67. [CrossRef]

25. Lang, G. The cherry industries in the USA: Current trends and future perspectives. Acta Hortic. 2019, 1235, 119-132. [CrossRef]

26. Robinson, T.; Hoying, S.; Sazo, M.M.; DeMarree, A.; Dominguez, L. A Vision for Apple Orchard Systems of the Future. Fruit $Q$ 2013, 21, 11-16.

27. Minas, I.; Cipollone, F.B.; Sterle, D. Near infrared spectroscopy can non-destructively assess the effect of canopy position and crop load on peach fruit maturity and quality. Acta Hortic. 2020, 1281, 407-412. [CrossRef]

28. Faust, M. Physiology of Temperate Zone Fruit Trees; John Wiley \& Sons, Inc.: Hoboken, NJ, USA, 1989.

29. Grossman, Y.; DeJong, T. Training and Pruning System Effects on Vegetative Growth Potential, Light Interception, and Cropping Efficiency in Peach Trees. J. Am. Soc. Hortic. Sci. 1998, 123, 1058-1064. [CrossRef]

30. Corelli-Grappadelli, L.; Marini, R.P. Orchard Planting Systems. In The Peach: Botany, Production and Uses; Layne, D.R., Bassi, D., Eds.; CABI: Cambridge, MA, USA, 2008; p. 264.

31. Chalmers, D.J.; Mitchell, P.D.; Jerie, P.H. The physiology of growth control of peach and pear trees using reduced irrigation. In Proceedings of the International Workshop on Controlling Vigor in Fruit Trees, Beltsville, MD, USA, 26-28 July 1983; Volume 146, pp. 143-150.

32. Génard, M.; Baret, F. Spatial and Temporal Variation of Light inside Peach Trees. J. Am. Soc. Hortic. Sci. 1994, 119, 669-677. [CrossRef]

33. Gullo, G.; Motisi, A.; Zappia, R.; Dattola, A.; Diamanti, J.; Mezzetti, B. Rootstock and fruit canopy position affect peach [Prunus persica (L.) Batsch] (cv. Rich May) plant productivity and fruit sensorial and nutritional quality. Food Chem. 2014, 153, $234-242$. [CrossRef]

34. Robinson, T.L. Interaction of Tree Form and Rootstock on Light Interception, Yield and Efficiency of 'Empire', 'Delicious' and 'Jonagold' apple Trees Trained to Different Systems. Acta Hortic. 1997, 451, 327-436. [CrossRef]

35. Nuzzo, V.; Dichio, B.; Palese, A.M.; Xiloyannis, C. Productivity and fruit quality in peach trees [Prunus persica (L.) Batsch]. The effect of the training system and light availability. Atti VI Giorn. Sci. SOI 2003, 1, 215-216.

36. Lauri, P.-E.; Grappadelli, L.C. Tree Architecture, Flowering and Fruiting-Thoughts on Training, Pruning and Ecophysiology. Acta Hortic. 2014, 291-298. [CrossRef]

37. DeJong, T.; Day, K.; Johnson, R. Physiological and Technological Barriers to Increasing Production Efficiency and Economic Sustainability of Peach Production Systems in California. Acta Hortic. 2008, 415-422. [CrossRef]

38. DeJong, T.M.; Day, K.R. Designing the Orchard. In Peaches, Plums, and Nectarines: Growing and Handling for Fresh Market; UCANR Pub.: Oakland, CA, USA, 1989; p. 3331.

39. Day, K.R.; DeJong, T.M.; Johnson, R.S. Orchard-system configurations increase efficiency, improve profits in peaches and nectarines. Calif. Agric. 2005, 59, 75-79. [CrossRef]

40. Neri, D.; Massetani, F.; Murri, G. Pruning and Training Systems: What Is Next? Acta Hortic. 2015, 429-443. [CrossRef]

41. Grappadelli, L.C. The Palmette Training System. Acta Hortic. 1998, 513, 329-336. [CrossRef]

42. Day, K.R.; Johnson, R.S.; DeJong, T.M. Evaluation of new techniques for improving stone fruit production, fruit quality, and storage performance: High density training trials. In California Tree Fruit Agreement Research Report; California Tree Fruit Agreement Annual Research: Sacramento, CA, USA, 1993; Volume 7.

43. Chalmers, D.; Van Den Ende, B.; Van Heek, L. Productivity and mechanization of the Tatura Trellis orchard [Peaches, pears, apricots]. HortScience 1978, 13, 517-521.

44. DeJong, T.M.; Day, K.R.; Doyle, J.F.; Johnson, R.S. The Kearney Agricultural Center perpendicular "V" (KAC-V) or-chard system for peaches and nectarines. HortTechnology 1994, 4, 362-367. [CrossRef]

45. Long, L.E.; Lang, G.A.; Whiting, M.D.; Musacchi, S. Cherry training systems. PNW Ext. 2015, 667, 1-63.

46. Tustin, D.; Van Hooijdonk, B.; Breen, K. The Planar Cordon-New planting systems concepts to improve light utilisation and physiological function to increase apple orchard yield potential. Acta Hortic. 2018, 1-12. [CrossRef]

47. Zhang, J.; Whiting, M.D.; Zhang, Q. Diurnal pattern in canopy light interception for tree fruit orchard trained to an upright fruiting offshoots (UFO) architecture. Biosyst. Eng. 2015, 129, 1-10. [CrossRef]

48. DeJong, T.M.; Tsuji, W.; Doyle, J.F.; Grossman, Y.L. Comparative economic efficiency of four peach production systems in California. HortScience 1999, 34, 73-78. [CrossRef]

49. Rogers, H.T. Stick with cling peaches. West. Fruit Grow. 1986, 106, 12. 
50. DeJong, T.; Tsuji, W.; Doyle, J.; Grossman, Y. Do high density systems really pay?-Evaluation of high density systems for cling peaches. Acta Hortic. 1997, 599-604. [CrossRef]

51. Hudson, J.P. Meadow orchards. Agriculture 1971, 78, 157.

52. Erez, A. Meadow orchard for the peach. Sci. Hortic. 1976, 5, 43-48. [CrossRef]

53. Erez, A. Peach Meadow Orchards. Acta Hortic. 1985, 405-412. [CrossRef]

54. Palmer, J.W.; Wünsche, J.N.; Meland, M.; Hann, A. Annual dry-matter production by three apple cultivars at four within-row spacings in New Zealand. J. Hortic. Sci. Biotechnol. 2002, 77, 712-717. [CrossRef]

55. Wünsche, J.N.; Lakso, A.N. The Relationship between Leaf Area and Light Interception by Spur and Extension Shoot Leaves and Apple Orchard Productivity. HortScience 2000, 35, 1202-1206. [CrossRef]

56. Sansavini, S.; Corelli-Grappadelli, L. Yield and Light Efficiency for High Quality Fruit in Apple and Peach High Density Planting. Acta Hortic. 1997, 559-568. [CrossRef]

57. Lordan, J.; Francescatto, P.; Dominguez, L.I.; Robinson, T.L. Long-term effects of tree density and tree shape on apple orchard performance, a 20 year study-Part 1, agronomic analysis. Sci. Hortic. 2018, 238, 303-317. [CrossRef]

58. Lordan, J.; Gomez, M.; Francescatto, P.; Robinson, T.L. Long-term effects of tree density and tree shape on apple or-chard performance, a 20 year study-Part 2, economic analysis. Sci. Hortic. 2019, 244, 435-444. [CrossRef]

59. Giuliani, R.; Magnanini, E.; Corelli-Grappadelli, L. Whole Canopy Gas Exchanges and Light Interception of Three Peach Training Systems. Acta Hortic. 1998, 309-318. [CrossRef]

60. Robinson, T.L.; Wünsche, J.; Lakso, A. The influence of orchard system and pruning severity on yield, light interception, conversion efficiency, partitioning index and leaf area index. In Proceedings of the V International Symposium on Orchard and Plantation Systems 349, Tel-Aviv, Israel, 21-26 June 1992; pp. 123-128.

61. Uberti, A.; Santana, A.S.; Lugaresi, A.; do Prado, J.; Louis, B.; Damis, R.; de Oliveira Fischer, D.L.; Giacobbo, C.L. Initial productive development of peach trees under modern training systems. Sci. Hortic. 2020, 272, 109527. [CrossRef]

62. De Salvador, F.; Fideghelli, C. Peach Training Systems to Improve Management Efficiency and to Reduce Costs. Acta Hortic. 1993, 349, 33-38. [CrossRef]

63. Rufato, L.; Rossi, A.; Picolotto, L.; Parizoto, E.; Fachinello, J. Evaluation of vegetative and productive response of two peach training systems (y system and central leader) in an icm orchard. Acta Hortic. 2004, 711-715. [CrossRef]

64. Giovannini, D.; Monastra, F. Tipologie e forme di allevamento per la peschicoltura meridionale. In Frutticoltura ad Alta Densità; Sansavini, S., Errani, A., Eds.; Edagricole: Bologna, Italy, 1998; pp. 217-236.

65. Caruso, T.; Di Vaio, C.; Inglese, P.; Pace, L.S. Crop load and fruit quality distribution within canopy of 'Spring Lady' peach trees trained to 'central leader' and 'Y shape'. In Proceedings of the IV International Peach Symposium 465, Bordeaux, France, 22-26 June 1997; pp. 621-628.

66. Farina, V.; Bianco, R.L.; Inglese, P. Vertical Distribution of Crop Load and Fruit Quality within Vase- and Y-shaped Canopies of 'Elegant Lady' Peach. HortScience 2005, 40, 587-591. [CrossRef]

67. Génard, M.; Bruchou, C. Multivariate analysis of within-tree factors accounting for the variation of peach fruit quality. Sci. Hortic. 1992, 52, 37-51. [CrossRef]

68. Wagenmakers, P.S.; Callesen, O. Light distribution in apple orchard systems in relation to production and fruit quality. J. Hortic. Sci. 1995, 70, 935-948. [CrossRef]

69. Lewallen, K.S.; Marini, R.P. Relationship between Flesh Firmness and Ground Color in Peach as Influenced by Light and Canopy Position. J. Am. Soc. Hortic. Sci. 2003, 128, 163-170. [CrossRef]

70. Anthony, B.M.; Chaparro, J.M.; Sterle, D.G.; Prenni, J.E.; Minas, I.S. Metabolic signatures of the true physiological impact of canopy light environment on peach fruit quality. Environ. Exp. Bot. 2021, 191, 104630. [CrossRef]

71. Anthony, B.; Serra, S.; Musacchi, S. Optimization of Light Interception, Leaf Area and Yield in "WA38": Comparisons among Training Systems, Rootstocks and Pruning Techniques. Agronomy 2020, 10, 689. [CrossRef]

72. Testolin, R.; Costa, G. Net photosynthesis: Sources of variation in peach canopy. Adv. Hortic. Sci. 1991, 5, 35-39. 